\title{
Effects of Chewing Gum on Recovery of Bowel Motility after Laparoscopic Colorectal Surgery in South Korea
}

\author{
$\mathrm{JiWoo} \mathrm{Hong}^{1}$, Hee Jung Jang ${ }^{2 \dagger}$ and Soon-Ok Ju${ }^{3}$ \\ ${ }^{1}$ Hallym University Sacred heart hospital, 14068, Korea \\ ${ }^{2}$ Division of Nursing, Hallym University, Chuncheon 24252, Korea \\ ${ }^{3}$ Hallym University Sacred heart hospital, 14068, Korea \\ ${ }^{1}$ E-mail: seasea2222@hallym.or.kr \\ ${ }^{2}$ Email: hjjang@hallym.ac.kr \\ ${ }^{3}$ Email: Soon@hallym.or.kr
}

\begin{abstract}
This study aimed to assess whether gum chewing affects bowel motility, including time to first passage of flatus, time to first feces, time to tolerance of oral fluid, and length of hospital stay after laparoscopic colorectal surgery. The current study had a non-equivalent control group and non-synchronized design. Sixty-four patients who underwent laparoscopic colorectal surgery were assigned to either a gum chewing group $(n=32$; experimental group) or a control group $(n=32)$. The patients in the experimental group chewed gum for 1 hour, 3 times a day, until they passed gas. Chewing gum led to significant differences in the first passage offlatus $(t=7.716, p<.001)$ and feces $(t=2.216, p=.030)$, time to tolerance of oral fluid $(t=4.404, p<.001)$, and length of hospital stay $(t=2.829, p=.006)$ between groups. This research concluded that chewing gum can be a useful intervention to shorten the time to the first passage of flatus and feces as well as to reduce the time to tolerance of oral fluid and length of hospital stay.
\end{abstract}

Keywords: Chewing gum, Laparoscopy, Colorectal surgery, flatus, feces

\section{Introduction}

Colorectal cancer is the third most-common cancer in Korea in both sexes, following thyroid cancer and stomach cancer. In males, colorectal cancer is the second mostcommon cancer following stomach cancer, whereas in females, it is the third mostcommon cancer following thyroid cancer and breast cancer [1]. The incidence of colorectal cancer in Korea is expected to markedly increase due to Westernized lifestyle and diet, and this condition may be fatal if its treatment is delayed; however, the associated 5year relative survival rate of colorectal cancer is higher as compared to other carcinomas if the tumor is removed by surgery, even in cases of advanced cancer [2]. The main treatments for cancer include surgical removal, radiation therapy and chemotherapy, which focus on the possibility of survival while reducing potential cancer recurrence and preventing metastasis to other organs $[3,4]$.

Laparoscopic surgery was recently introduced for surgical removal, and its advantages compared to laparotomy include reduced postoperative pain, faster recovery, reduced analgesic use, shorter length of hospital stay, quicker rehabilitation, and cosmetic benefit; hence, laparoscopic surgery is often recommend for colorectal cancer [5]. However, postoperative pain at the surgical site, thirst, nausea, vomiting, and abdominal detention

† corresponding author E mail: hjjang@hallym.ac.kr 
due to temporary ileus may typically appear as postoperative complications causing patient discomfort [6]. Immediately after enterectomy, patients may suffer from abdominal detention and nausea caused by reduced bowel motility and intestinal swelling; moreover, colorectal cancer patients are the most common recipients of this surgery [7]. Therefore, to reduce patient discomfort, the procedure adopted should help restore bowel motility so that gas can be quickly discharged.

Several studies focusing on the resolution of discomfort have reported that early oral intake shortens the duration of ileus and reduces the time to normal diet $[8,9]$. However, as early oral intake can lead to complications such as surgical anastomotic leakage or aspiration pneumonia $[8,10]$, sham feeding - such as the action of chewing gum, instead of dietary intake - has been proposed. Sham feeding refers to a method wherein food is prevented from entering the stomach, and although people can see, smell, and chew the food, they do not swallow the food. Gum chewing is known to stimulate vagal nerves, which subsequently increases gastric and bowel motility, by increasing the secretion of plasma gastrin, neurotensin, and pancreatic polypeptides [11]. In particular, chewing gum is a type of sham feeding that is convenient, inexpensive, and easy to implement. It is recommended as a safe intervention for patients undergoing colorectal surgery because there have been no reported adverse effects of gum chewing in these patients [12]. In addition, chewing gum has been reported to be effective in helping postoperative recovery and reducing the length of hospital stay [10].

Most of the studies on the effects of chewing gum have included patients undergoing open surgery, while the studies on the effects of chewing gum in patients undergoing laparoscopic colorectal surgery are rare [13].

Therefore, in the present study, we aimed to assess whether chewing gum is an effective intervention to help postoperative recovery and reduce the length of hospital stay after laparoscopic colorectal surgery by shortening the time to first passage of flatus and time to first feces, as well as preventing ileus in relation to bowel motility; we also sought to use these findings to establish guidelines for using gum chewing in such patients' clinical practice.

\subsection{Purpose}

In the present study, we aimed to assess whether chewing gum can be an effective intervention to help postoperative recovery. We also assessed how it can reduce the length of hospital stay after laparoscopic colorectal surgery by reducing the time to first passage of flatus and time to first feces in patients undergoing laparoscopic colorectal surgery.

\subsection{Hypotheses}

1) The first hypothesis: The time to the first passage of flatus will be shorter in the gum chewing experimental group than in the non-gum chewing control group.

2) The second hypothesis: The time to first feces will be shorter in the experimental group than in the control group.

3) The third hypothesis: The time to first meal (including beverage) will be shorter in the experimental group than in the control group.

4) The fourth hypothesis: The length of postoperative hospital stay will be shorter in the experimental group than in the control group.

\section{Methods}




\subsection{Research Design}

In the present quasi-experimental study, using a non-equivalent control group and nonsynchronized design, we aimed to investigate the effect of chewing gum on the recovery of bowel motility in patients undergoing laparoscopic colorectal surgery.

\subsection{Participants}

The subjects were adult patients who underwent laparoscopic surgeries under general anesthesia such as hemicolectomy (Lt, Rt), anterior resection (AR), low anterior resection (LAR), or abdominoperineal resection (APR), who were hospitalized at the surgical ward in H University Hospital, and who met the following criteria:

1) Subjects who had clear consciousness and were capable of communicating.

2) Subjects who agreed to participate in this study.

The exclusion criteria were:

1) Subjects who had disability in chewing gum due to oral disease or tooth defects.

2) Subjects who concurrently underwent gastrectomy and small intestine resection.

3) Subjects with nasogastric tube intubation.

4) Subjects who received a psychiatric diagnosis or were taking psychiatric drugs.

Given the effect size of 0.7 (medium) by the G Power 3.0 program, the significance level of 0.05 , the test power of $80 \%$, and the use of the t-test, the number of subjects required was 68; of these subjects, 2 dropped out of the study as a result of chewing gum discomfort during data collection among the experimental group, whereas 2 were excluded from the control group due to incomplete data collection; all in all a total of 64 subjects were included in the study. The subjects were informed regarding the purpose and method of this study, that gum chewing would not harm them, that their participation in the study could be discontinued at any time during the study period as per their preference, and that their personal information would be protected and related data should be discarded after the study. The subjects were also informed that patient anonymity would be maintained, and the subjects voluntarily consented to participate in the study.

\subsection{Data Collection}

Data collection for this study was conducted in patients undergoing laparoscopic colorectal surgery who were either assigned to the experimental group comprising patients hospitalized from May 2013 to September 2013, or the control group comprising of patients hospitalized from January 2013 to April 2013.

The collected data included the general characteristics of the subjects and the subjects' age, gender, surgical method, operation time, and history of prior surgery as factors affecting the recovery of bowel motility. This information was collected from the medical records. Early ambulation abnormality was assessed in a uniform manner, wherein each patient walked around the corridor 3 times $(420 \mathrm{~m})$, starting from the first day of arrival in the ward room after surgery. The time to first passage of flatus, time to first feces, time to first dietary intake, and length of hospital stay after surgery were used as measures of recovery of postoperative bowel motility. Two nurses at the relevant ward were educated regarding data collection and trained for data collection. The 2 nurses collected data on the time to the first passage of flatus, time to first feces, time to first dietary intake after surgery through subjects' self-report, and data on the length of hospital stay from the doctor's hospital discharge prescription.

\subsection{Experimental Procedure}


Sugarless Xylitol gum of L Company was used for gum chewing as the experimental treatment in this study. The gum was supplied to patients 3 times a day at 8:00 am, 1:00 $\mathrm{pm}$, and 6:00 pm, starting from the day of admission to the ward after surgery; this treatment was based on studies by Quah, et al., [14], Schuster, et al., [10], Bang, et al., [6], and Kim, et al., [15]. The duration of gum chewing was 1 hour, which was based on the studies by Schuster, et al., [10] and Bang et al [6]

Gum chewing was discontinued following the self-reporting of the first passage of flatus from the bowel, which was based on certain studies $[6,10,14,16,17]$ wherein oral intake was initiated after the passage of flatus, after which gum chewing was discontinued.

\subsection{Data analysis}

The results of this study were statistically analyzed using SPSS PC+ Program Ver. 19.0. The number of study subjects was 68 , including 32 in the experimental group and 32 in the control group, and 4 subjects who were excluded due to incomplete data.

1) The general characteristics of the subjects were analyzed by frequency, percentage, average, and standard deviation.

2) Homogeneity test between groups was analyzed using the $\chi^{2}$ test and t-test.

3) Difference test between groups for hypothesis testing was analyzed using the $\chi^{2}$ test and t-test.

\section{Results}

\subsection{Homogeneity of General and Clinical Characteristics between the 2 Groups}

Of the 32 subjects in the experimental group, 21 were men $(65.63 \%)$ and 11 were women $(34.37 \%)$. Of the 32 subjects in the control group, 17 were men $(51.13 \%)$ and 15 were women $(46.87 \%)$. Both groups had more men than women, and no significant difference was noted between the 2 groups $\left(\chi^{2}=1.641, p=.305\right)$.

With regard to age distribution, the mean age of the experimental group and control group was $62.40 \pm 16.34$ years and $65.68 \pm 1.80$ years, respectively, and no significant difference was noted between the 2 groups $(t=.921, p=.361)$. With regard to age group, no significant difference was noted between groups $\left(\chi^{2}=1.330, p=.797\right)$. In terms of underlying disease, $8(25 \%)$ subjects had hypertension and $6(6 \%)$ subjects had hypertension and diabetes in the experimental group, whereas 12 (37.50\%) subjects had hypertension, $5(15.62 \%)$ subjects had hypertension and diabetes, and $2(6.25 \%)$ subjects had other diseases (appendicitis, uterine myoma) in the control group; no significant difference in the underlying disease was noted between the 2 groups $\left(\chi^{2}=3.697, \mathrm{p}=.296\right)$.

With regard to the type of surgery, 12 (37.5\%) underwent hemicolectomy, $9(28.13 \%)$ underwent anterior resection, $8(25 \%)$ underwent low anterior resection, $3(9.37 \%)$ and underwent abdominoperineal resection in the experimental group, whereas 11 (34.48\%) underwent hemicolectomy, 7 (21.88\%) underwent anterior resection, 8 (34.37\%) underwent low anterior resection, and $3(9.37 \%)$ underwent abdominoperineal resection in the control group; no significant difference was noted in the type of operation between groups $(\mathrm{t}=.767, \mathrm{p}=.857)$. The operation time was $330.0 \pm 42.50 \mathrm{~min}$ in the experimental group and $316.0 \pm 42.53 \mathrm{~min}$ in the control group; no significant differences were noted between the groups $(\mathrm{t}=-1.230, \mathrm{p}=.222)$.

The homogeneity test for the general characteristics of the experimental and control group was performed using the $\chi^{2}$ test and t-test. No significant differences were noted between the groups, as shown in Table 1; hence, it was found to be a homogenous population. 
Table 1. Homogeneity of the General and Clinical Characteristics between the 2 Groups

\begin{tabular}{|c|c|c|c|c|}
\hline $\begin{array}{l}\text { characteris- } \\
\text { tics }\end{array}$ & $\begin{array}{l}\text { experi- } \\
\text { mental group } \\
(n=32)\end{array}$ & $\begin{array}{c}\text { control } \\
\text { group } \\
(\mathbf{n}=32)\end{array}$ & $\begin{array}{l}x^{2} \\
\text { or } t\end{array}$ & $\mathbf{p}$ \\
\hline \multicolumn{5}{|l|}{ gender } \\
\hline female & $21(65.63 \%)$ & $17(53.12 \%)$ & \multirow{2}{*}{1.641} & \multirow{2}{*}{.305} \\
\hline male & $11(34.37 \%)$ & $15(46.88 \%)$ & & \\
\hline age(year) & $62.40 \pm 16.34$ & $65.68 \pm 11.80$ & .921 & .361 \\
\hline \multicolumn{5}{|l|}{ an age group } \\
\hline $20 \sim 39$ & 2 & 1 & \multirow{4}{*}{1.330} & \multirow{4}{*}{.797} \\
\hline $40 \sim 59$ & 9 & 9 & & \\
\hline $60 \sim 79$ & 17 & 19 & & \\
\hline above 80 & 4 & 3 & & \\
\hline \multicolumn{5}{|c|}{ History of baseline disease } \\
\hline none & $18(56.25 \%)$ & $13(40.63 \%)$ & \multirow{4}{*}{3.697} & \multirow{4}{*}{.296} \\
\hline hypertension & $8(25.00 \%)$ & $12(37.50 \%)$ & & \\
\hline $\begin{array}{l}\text { hypertension } \\
\text { and diabetes }\end{array}$ & $6(18.75 \%)$ & $5(15.62 \%)$ & & \\
\hline others disease & $0(0 \%)$ & $2(6.25 \%)$ & & \\
\hline $\begin{array}{l}\text { operating } \\
\text { time(min) }\end{array}$ & $330.0 \pm 42.50$ & $316.0 \pm 42.53$ & -1.230 & .222 \\
\hline \multicolumn{5}{|c|}{ Type of operation } \\
\hline hemicolectomy & $12(37.50 \%)$ & $11(34.38 \%)$ & \multirow{4}{*}{.767} & \multirow{4}{*}{.857} \\
\hline $\begin{array}{l}\text { anterior } \\
\text { resection }\end{array}$ & $9(28.13 \%)$ & $7(21.88 \%)$ & & \\
\hline $\begin{array}{l}\text { low anterior } \\
\text { resection }\end{array}$ & $8(25.00 \%)$ & $11(34.37 \%)$ & & \\
\hline $\begin{array}{c}\text { abdomino- } \\
\text { perineal resection }\end{array}$ & $3(9.37 \%)$ & $3(9.37 \%)$ & & \\
\hline
\end{tabular}

\subsection{Hypothetic Verifications}

1) The first hypothesis: When the first hypothesis - the time to the first passage of flatus will be shorter in the gum chewing experimental group than in the non-gum chewing control group - was verified by using the t-test, the time to the first passage of flatus was $2.96 \pm 1.25$ days in the experimental group and $5.37 \pm 1.23$ days in the control group; the difference in these values was statistically significant $(t=7.716, p<.001)$, and hence, the first hypothesis is supported, as shown in Table 2.

Table 2. Time to the First Passage of Flatus

\begin{tabular}{|c|c|c|c|c|}
\hline variable & $\begin{array}{c}\text { experimental } \\
\text { group }(\mathbf{n = 3 2})\end{array}$ & $\begin{array}{c}\text { control } \\
\text { group }(\mathbf{n}=32)\end{array}$ & $\mathbf{t}$ & $\mathbf{p}$ \\
\hline $\begin{array}{c}\text { time to first pas- } \\
\text { sage of flatus(day) }\end{array}$ & $2.96 \pm 1.25$ & $5.37 \pm 1.23$ & 7.716 & .000 \\
\hline
\end{tabular}

2) The second hypothesis: When the second hypothesis - the time to first feces is shorter in the experimental group than in the control group - was verified by using the ttest, as shown in Table 3, the time to first feces was found to be $4.53 \pm 1.81$ days in the 
experimental group and $5.53 \pm 1.79$ days in the control group; the difference in these values was statistically significant $(\mathrm{t}=2.216, \mathrm{p}=.030)$, and hence, the second hypothesis is supported.

Table 3. Time to First Feces

\begin{tabular}{|l|l|c|c|c|}
\hline Variable & $\begin{array}{c}\text { experimental } \\
\text { group }(\mathbf{n}=32)\end{array}$ & $\begin{array}{c}\text { control } \\
\text { group }(\mathbf{n}=32)\end{array}$ & $\mathbf{t}$ & $\mathbf{p}$ \\
\hline $\begin{array}{l}\text { time to first } \\
\text { feces(day) }\end{array}$ & $4.53 \pm 1.81$ & $5.53 \pm 1.79$ & 2.216 & .030 \\
\hline
\end{tabular}

3) The third hypothesis: When the third hypothesis - the time to the first meal (including beverage) will be shorter in the experimental group than in the control group-was verified by using the t-test, as shown in Table 4, the time to sipping water was found to be $4.4 \pm 2.04$ days in the experimental group and $5.59 \pm 1.24$ days in the control group $(\mathrm{t}$ $=2.658, \mathrm{p}=.010$ ) and time to liquid diet intake was found to be $5.25 \pm 0.91$ days in the experimental group and $6.46 \pm 1.26$ days in the control group; the differences in these values were found to be statistically significant $(t=4.404, p<.001)$ and hence, the third hypothesis is also supported.

Table 4. Time to Tolerance of Oral Fluid

\begin{tabular}{|c|c|c|c|c|}
\hline variables & $\begin{array}{c}\text { experimental } \\
\text { group (n=32) }\end{array}$ & $\begin{array}{c}\text { control } \\
\text { group }(\mathbf{n}=32)\end{array}$ & $\mathbf{t}$ & $\mathbf{p}$ \\
\hline $\begin{array}{c}\text { time to having } \\
\text { sips (day) }\end{array}$ & $4.46 \pm 2.04$ & $5.59 \pm 1.24$ & 2.658 & .010 \\
\hline $\begin{array}{c}\text { time to liquid } \\
\text { diet(day) }\end{array}$ & $5.25 \pm 0.91$ & $6.46 \pm 1.26$ & 4.404 & .000 \\
\hline
\end{tabular}

4) The fourth hypothesis: When the fourth hypothesis - the length of postoperative hospital stay will be shorter in the experimental group than in the control group-was verified by using the t-test, as shown in Table 5, the length of postoperative hospital stay was found to be $11.21 \pm 2.63$ days in the experimental group and $15.15 \pm 7.41$ days in the control group; the difference in these values was statistically significant $(\mathrm{t}=2.829, \mathrm{p}=$ .006), and thus, the fourth hypothesis is supported.

Table 5. Length of Postoperative Hospital Stay

\begin{tabular}{|c|c|c|c|c|}
\hline variable & $\begin{array}{c}\text { experimental } \\
\operatorname{group}(\mathbf{n}=32)\end{array}$ & $\begin{array}{c}\text { control } \\
\operatorname{group}(\mathbf{n}=32)\end{array}$ & $\mathbf{t}$ & $\mathbf{p}$ \\
\hline $\begin{array}{c}\text { length of post- } \\
\text { operative hospital } \\
\text { stay }\end{array}$ & $11.21 \pm 2.63$ & $15.15 \pm 7.41$ & 2.829 & .006 \\
\hline
\end{tabular}

\section{Conclusion}

In the present study, with the first hypothesis (time to first passage of flatus will be shorter in gum-chewing experimental group than in non-gum chewing control group) was verified by using the t-test, the time to the first passage of flatus was found to be 2.96 days in the experimental group and 5.37 days in the control group; the difference in these values was statistically significant, and thus, the first hypothesis is supported. When the second hypothesis (the time to first feces will be shorter in the experimental group than in the control group) was verified by using the t-test, the time to first feces was found to be 4.53 days in the experimental group and 5.53 days in the control group; the difference in 
these values was statistically significant, and thus, the second hypothesis is also supported. When the third hypothesis (the time to first meal will be shorter in the experimental group than in the control group) was verified by using the t-test, the time to sipping water was found to be 4.4 days in the experimental group and 5.5 days in the control group, whereas the time to liquid diet intake was found to be 5.2 days in the experimental group and 6.4 days in the control group; the differences in these values were statistically significant, and thus, the third hypothesis is also supported. When the $4^{\text {th }}$ hypothesis (the length of post-operative hospital stay will be shorter in the experimental group than in the control group) was verified by using the t-test, the length of post-operative hospital stay was found to be 11.21 days in the experimental group and 15.15 days in the control group, which was shown to be statistically significant, and thus, the fourth hypothesis is also supported.

In conclusion, this study found that gum chewing in patients undergoing laparoscopic colorectal surgery can be an effective intervention to facilitate the passage of flatus and feces, shorten the time to dietary intake, and shorten the length of hospital stay by promoting bowel motility.

\section{References}

[1] "Cancer facts \& Figures", National cancer information center, South Korea, (2013).

[2] K. S. Choi, J. A. Park and J. Lee, "The Effect of Symptom Experience and Resilience on Quality of Life in Patients with Colorectal Cancers," Asian Oncol Nurs, vol. 12, no. 2, (2012), pp. 61-68.

[3] H. J. Kim, S. H. Chu, J. S. Yoo and N. K. Kim, "Nutritional Risk and Physical Activity on Quality of Life in Patients with Colorectal Cancer," Asian Oncol Nurs, vol. 14, no. 6, (2014), pp. 66-73.

[4] B. Y. Ji and J. Y. Park, "Perceived understanding and educational need of patient with colorectal cancer," Journal of the Korean Data Analysis Society, vol. 15, (2013), pp. 211-222.

[5] "Korean academy of medical sciences", Korean clinical guideline for colon and rectal cancer V1.0: Korean academy of medical sciences, (2012).

[6] S. Y. Bang, G. J. Jeong, H. Y. Jeong and S. H. An, "The Effects of Gum-Chewing on the Recovery of Bowel Movement and Oral Cavity Discomfort after Abdominal Surgery", Journal of Korean Clinical Nursing Research, vol. 14, (2008), pp. 15-25.

[7] K. W. Jung, Y. J. Won, H. J. Kong, C. M. Oh, H. G. Seo and J. S. Lee, "Cancer Statistics in Korea: Incidence, Mortality, Survival and Prevalence in 2010," Cancer Res Treat, vol. 45, (2013), pp. 1-14, 03.

[8] P. Mattei and J. Rombeau, "Review of the Pathophysiology and Management of Postoperative Ileus," World Journal of Surgery, vol. 30, (2006), pp. 1382-1391.

[9] D. Stewart and K. Waxman, "Management of Postoperative Ileus," American Journal of Therapeutics, vol. 14, (2007), pp. 561-566.

[10] R. Schuster, N. Grewal, G. C. Greaney and K. Waxman, "GUm chewing reduces ileus `after elective open sigmoid colectomy," Archives of Surgery, vol. 141, (2006), pp. 174-176.

[11] S. Y. Park and M. Chung, "Can Gum Chewing Reduce Postoperative Ileus after Open Abdominal Surgery?," Annal s of surgical treatment and research, vol. 77, (2009), pp. 306-309.

[12] H. Leier, "Does gum chewing help prevent impaired gastric motility in the postoperative period?," J Am Acad Nurse Pract, vol. 19, (2007) March, pp. 133-136.

[13] J. Hong, H. J. Jang and S.-O. Ju, "Effects of chewing gum on recovery of bowel motiltity among patients after laparoscopic colerectal surgery," in Advanced Science and Technology Letters, (2015), pp. 33-37.

[14] H. M. Quah, A. Samad, A. J. Neathey, D. J. Hay and A. Maw, "Does gum chewing reduce postoperative ileus following open colectomy for left-sided colon and rectal cancer? - a prospective randomized controlled trial," Colorectal Disease, vol. 8, (2006), pp. 64-70.

[15] S. Kim Sam, N. Lee Eun, S. Kim Hack, K. Kim Min, S. Lee Kyoung, J. Nam Hye, et al., "Effects of Gum-chewing on the Recovery of Bowel Motility and Length of Hospital Stay after Surgery for Colorectal Cancer," Asian Oncol Nurs, vol. 10, no. 8, (2010), pp. 191-198.

[16] Q. Zhang and P. Zhao, "Influence of Gum Chewing on Return of Gastrointestinal Function after Gastric Abdominal Surgery in Children," European Journal of Pediatric surgery, vol. 18, (2008), pp. 44-46.

[17] I. Hirayama, M. Suzuki, M. Ide, T. Asao, and H. Kuwano, "Gum-chewing Stimulates Bowel Motility after Surgery for Colorectal Cancer," Hepato-gastroenterology, vol. 53, (2006), pp. 206-208.

\section{Authors}




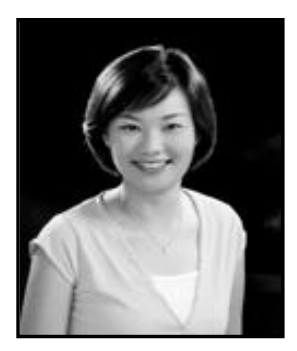

Ji Woo Hong, is a nurse in Hallym University Sacred Heart Hospital. She graduated from Department of Nursing, Woosuk University in 2005 . Her current research interest is care of patients and their family with gastrointestinal disease.

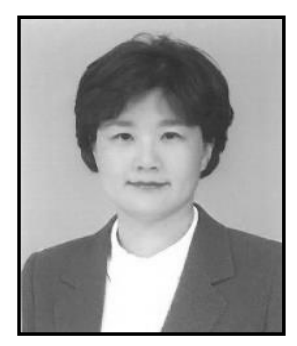

Hee Jung Jang, is a professor in Division of Nursing, Hallym University since 1997. She received B.S, M.S, and Ph.D of Nursing in Ewha womans University. Her research interests are Middle aged health, medical- surgical Nursing including care of patients with colorectal cancer.

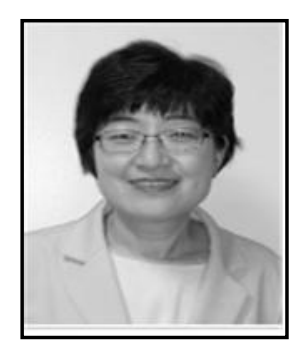

Soon-Ok Ju, is a head nurse in Hallym University Sacred Heart Hospital. She is currently working toward M.S degree at nursing graduate school of Hallym University. She graduated Korea National Open University for B.S, and received diploma in Chuncheon college of Nursing at 1985. Her research interest is surgical nursing. 